\title{
PRINCIPIO DE BUENA FE ${ }^{1}$
}

\author{
PRINCIPLE OF GOOD FAITH
}

Por María Amelia Assaad ${ }^{(*)}$

Estela María Feliciotti (**)

\begin{abstract}
Resumen: Se estructura un análisis del principio de buena fe a la luz del Código Civil y Comercial de la Nación, analizando su sistematización, antecedente y ubicación. Se centra el análisis del significado del Principio y su evolución. Se estudia su valoración y funciones en doctrina y jurisprudencia. Asimismo, se analiza sus efectos en los contratos.
\end{abstract}

Palabras Claves: Principio de Buena Fe - Contratos - Código Civil y Comercial

Abstract: An analysis of the principle of good faith is structured in the light of the National Civil and Commercial Code, analyzing its systematization, background and location. The analysis of the meaning of the Principle and its evolution is centered. Its evaluation and functions in doctrine and jurisprudence are studied. Its effects on contracts are also analyzed.

Keywords: Principle of good faith. Contracts - Civil and Commercial Code

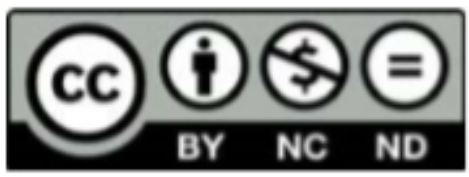

Artículo publicado bajo Licencia Creative Commons Atribución-No Comercial-Sin

Derivar. (C) Universidad Católica de Córdoba

DOI http://dx.doi.org/10.22529/adc.2019(13)09

\footnotetext{
${ }^{1}$ Artículo recibido el 10 de septiembre y aprobado para su publicación el 5 de noviembre de 2019.

(*) Notaria egresada de la Universidad Católica de Córdoba- Abogada egresada de la Universidad Católica de Córdoba-Escribana General de la Escribanía General de Gobierno de la Provincia de Córdoba dependiente de Fiscalía de Estado-Diplomada en Gestión de Gobierno por la Universidad de Belgrano de la República Argentina- Exponente, Coordinadora de ponencias y debate en Encuentros de Escribanos de Gobierno de la República Argentina-Integrante del equipo de trabajo y desarrollo del Compendio Normativo del Gobierno de la Provincia de Córdoba. Mail: amelia.assaad@gmail.com

(**) Egresada de abogada en el año 1985 en la Universidad Nacional de Córdoba, fui adscripta en la catedra "A" de Derecho Romano I y II entre los años 1986 al 1990. Ingrese en la Escribanía General de Gobierno en el año 1989. En el año 2010 me recibí de Escribana en el la U.N.C. Hoy cumplo función como Escribana Sustituta de la Escribanía General de Gobierno de la Provincia de Córdoba. Mail: mariaestela_1@hotmail.com
} 
"Y así que seáis más sabios, pero, por sobre todo, $y$ ello es lo que más importa, que seáis cada día más buenos”

(López Palop, Eduardo Sesión de apertura de la Semana Notarial de Santander de 1948)

\section{Introducción}

El principio de buena fe se encuentra receptado en el Capítulo 3 denominado Ejercicio de los Derechos, dentro del Título Preliminar del Código Civil y Comercial de la Nación (C.C. y C.N).

El art. 9 del Código Civil y Comercial de la Nación expresa que "los derechos deben ser ejercidos de buena fe".

Analizando la ubicación de este Principio dentro del Código podemos advertir que se perfila con carácter de regla general como una idea directriz para el ejercicio de todos los derechos fundamentales del derecho privado. Este principio se repite en innumerables veces a lo largo de todo el C.C. y C.N, complementándose con reglas específicas existentes en materia de obligaciones, contratos, derechos reales, entre otras. Implica una manera del deber actuar; como punto de partida se presume la buena fe, la honestidad, la lealtad en las conductas de las personas.

En los fundamentos del proyecto (III.6,1) dice que tiene como destinatario principal a los ciudadanos. Se trata del primer principio general que se encuentra de manera expresa y precisa, hace al ejercicio de los derechos subjetivos dirigidos al ciudadano habiendo tenido un gran desarrollo en la doctrina y jurisprudencia nacional al que se le otorga un lugar de relevancia.

La buena fe se extiende a todo el derecho privado, incluye el ejercicio de los derechos y cumplimiento de los deberes y toda conducta con eficacia o trascendencia jurídica. No solo tiene incidencia en la justicia contractual, sino también en las obligaciones que nacen de la 
declaración unilateral de la voluntad, el resarcimiento del daño, los derechos reales y las situaciones jurídicas familiares"2.

\section{Significado y Acepciones}

La buena fe es un elemento natural de la vida humana que en el mundo jurídico actúa como principio general para regular la armónica convivencia entre los hombres, funciona como control de la sociabilidad en el ejercicio de los derechos subjetivos. Constituye un concepto jurídico indeterminado que debe ser precisado en cada caso concreto analizando el problema; representa un punto de conexión entre lo ético y lo jurídico. La buena fe es vista como la conducta humana media ya implique creer en lo aparente como real o signifique lealtad.

La buena fe proviene del latín, bona fides, es un principio general del derecho, consistente en el estado mental de honradez, de convicción en cuanto a la verdad o exactitud de un asunto, hecho u opinión, título de propiedad, o la rectitud de una conducta. ${ }^{3}$

Alsina Atienza sostiene que el deber de conducirse con probidad se traduce en las recíprocas relaciones de las partes contratantes, en sus relaciones con el orden Publico, en el ejercicio de los derechos y en las reglas de la prueba. ${ }^{4}$

Diez Picasso expone que, si la "buena fe" es un modelo o arquetipo de conducta social, hay una norma jurídica que impone a la persona el deber de comportarse de "buena fe" en el tráfico jurídico, cada persona debe ajustar su propia conducta al arquetipo de la conducta social reclamada por la idea imperante. Se exige esta conducta no solo desde la limitación de una conducta deshonesta sino además en una exigencia positiva siendo ejemplo los deberes de cooperación y de diligencia. ${ }^{5}$

Según Lavalle Cobo la buena fe alude a la recíproca lealtad de las partes en el curso de las relaciones contraídas, la que debe apreciarse objetivamente, para lo cual, debe aplicarse "a cada situación el criterio de lo que hubieran hecho dos personas honorables y razonables".

${ }^{2}$ Lorenzetti (dir) Código Civil y Comercial, t.I pag.53.

${ }^{3}$ Diccionario de la Real Academia Española

${ }^{4}$ Alsina Atienza, Dalmiro, Efectos Jurídicos de la "buena fe"

${ }^{5}$ Diez Picazo, La doctrina de los propios actos. Edit. Bosch 
El principio de buena fe es de contenido, no de forma, existen reglas que nos permiten establecer cuando estamos ante una conducta justa, ante un principio problemático llamado a actuar en cada oportunidad y el juez es quien debe analizar cada caso concreto.

Este principio en el nuevo código se refiere a un concepto y criterio valorativo que no está en la ley, surge de la sociedad, de una exigencia ética que proviene de la convivencia social. Supone una conducta media, en lo que se refiere a la colaboración con el otro, la cual debe ser activa, evitar el daño, ejecutar los negocios lealmente teniendo en cuenta los usos y costumbres del lugar concluyendo con el deber actuar con diligencia para conocer de las situaciones, el alcance del derecho y la obligación de acuerdo con las posibilidades y circunstancias de cada caso.

Sin lugar a duda cuando hablamos de buena fe nos referimos a la conducta del hombre medio, implica creer en lo aparente como real y un deber de lealtad.

\section{Historia del principio de buena fe}

El principio de buena fe surge como consecuencia de un proceso histórico. Nace en el derecho privado para plasmarse en todo ordenamiento jurídico, el cual evoluciona y se convierte luego en una regla general.

Todos los pueblos de la antigüedad, y muy especialmente los romanos, le reconocen gran importancia a la "fides" recubriéndola incluso del carácter religioso e incorporándola a la vida y a la conciencia social. Nace así entre otras múltiples aplicaciones la "bona fides" aludiéndose a la corrección en el comportamiento.

Se encontraba presente la bona fides exigiendo del vendedor la transferencia efectiva de la propiedad del bien. De manera que el concepto originario de buena fe estuvo siempre atado o ligado al deber de comportamiento probo y leal frente a la otra parte en el contrato, es decir, a lo que hoy entendemos como buena fe objetiva.

De los Mozos expresa que se califica de "bona fides" lo que de una manera u otra coincide con el ideal general expresado en virtud de conexiones casuísticas y retóricas (topoi) que responden a una misma sustancia, la fidelidad. 
El rigorismo y formalismo del derecho romano llegó a anteponer la técnica de la contratación a la ética que se desprendía del respeto pactado.

Posteriormente, Santo Tomás sostuvo que la justicia es la propia rectitud que se constituye acerca de las cosas exteriores usadas por el hombre, las cuales son, en definitiva, la materia de la justicia. Pero esa rectitud implica una ordenación hacia el fin debido y a la ley divina, que es la regla de la voluntad humana y es común a toda virtud. Por otro lado, Platón se refería a la justicia "como la recta ordenación de todas las facultades y virtudes del hombre". Se trata, entonces, de la honestidad llevada al terreno jurídico, en palabras de Ulpiano: "Honeste vivere, neminem laedere et suum", que se traduce en: "Vivir honestamente, no dañar al otro y dar a cada quien lo que le corresponde"; y de aquí la esencial importancia del principio que hemos analizado.

Sucede que en el Código Civil de Vélez Sarsfield el principio de la buena fe estaba, como tal, inserto en el art. 1198 que decía en su primera parte: "Los contratos deben celebrarse, interpretarse y ejecutarse de buena fe y de acuerdo con lo que verosímilmente las partes entendieron o pudieron entender, obrando con cuidado y previsión". Es claro que ello estaba focalizado en los contratos, ámbito en el cual se desarrolló y afianzó el principio en análisis hasta ser receptado actualmente por el C.C .y C con un carácter de regla general, dándole el lugar de privilegio que debe y merece tener.

En los Fundamentos del Anteproyecto se dijo que: "Las cláusulas generales relativas a la buena fe, el abuso, el fraude, y otras, tuvieron un proceso histórico de generalización creciente; ya que primero fueron utilizados en obligaciones, contratos y derechos reales específicos, luego extendieron su aplicación a las obligaciones, los contratos, los derechos reales, de familia y de sucesiones en general, y finalmente fueron adoptados como principios generales en todo el derecho privado".

El principio de la buena fe impone a las personas el deber de obrar correctamente, como lo haría una persona honorable, diligente y prudente; en palabras del maestro Vélez Sarsfield, como un buen padre de familia. El principio de la buena fe es aquel que encarna la idea de honestidad en las relaciones jurídicas y la circulación de bienes en general, teniendo su fundamento en la garantía de justicia y equidad. 


\section{Clasificación de la buena fe}

Doctrinariamente se han distinguido dos especies de buena fe: la buena fe- lealtad y la buena fe-creencia.

El art. 9 del C.C y C contempla la buena fe como "apariencia", es decir las partes deben confiar en las situaciones tal como se les presentan y la buena fe como "lealtad" en las relaciones jurídicas, siendo utilizada en la interpretación y en la integración como fuente de deberes secundarios de conducta y como elemento correctivo del ejercicio de los derechos". Según Atilio A. Alterini, hay "buena fe-creencia" (objetiva) cuando versa justificadamente acerca de la titularidad de un derecho y de apariencia implica el estado objetivo del que deriva el estado subjetivo de la creencia que, cuando es generalizada, se convierte en error común; y error commun is facit jus. La buena "fe-probidad" (subjetiva) importa el comportamiento leal, el comportamiento honesto, en la celebración y cumplimiento del acto y es, desde otro enfoque, presupuesto del reconocimiento de ciertas facultades, o derechos subjetivos. es el comportamiento del hombre de bien, que actúa correctamente en la convivencia social. ${ }^{6}$

Mosset Iturraspe expresa y diferencia dos tipos de buena fe dentro de este principio. Por un lado cuando ordena conductas probas, dignas, leales y descarta todo proceder contrario a esas pautas (buena fe objetiva) y por el otro cuando manda a ajustarse a la apariencia, a la que el otro pueda entender para no defraudar la confianza suscitada (buena fe subjetiva).

Se lo puede clasificar según dos tipos: a) 1) buena fe - lealtad u objetiva es aquella que es debida entre personas relacionadas jurídicamente y 2) buena fe - creencia o subjetiva es cuando el sujeto cree poseer legítimamente un derecho b) La buena fe en la interpretación del acto: implica la confianza ante una declaración de voluntad de que sus efectos serán los previsibles, por normales, en un caso dado. Los jueces no deben admitir la reserva mental, ni aceptar como válida una diferente acepción de los vocablos que alguna de las partes diga haber querido significar para salvar su responsabilidad. Deben atenerse al uso común. c) La buena fe en la ejecución del acto: obliga al cumplimiento de las obligaciones de la forma que, en cada caso, es dable esperar entre personas de conducta recta: 1) los jueces no deben

${ }^{6}$ Alterini, A. Derecho de las obligaciones civiles y Comerciales Bs. As. Abeledo Perrot 1996, pag. 150 
atender estrictamente a las acepciones técnico-jurídicas de las palabras empleadas, sino a la voluntad de las partes; 2) Para interpretar la voluntad es útil atenerse a los usos y costumbres sociales; 3) La buena fe y su rol en los contratos de adhesión: se alude a la injusticia de la parte fuerte que aprovecha su posición frente a la débil. Se hace notar que ante la contradicción entre cláusulas impresas y otras manuscritas o mecanografiadas, privan las últimas. ${ }^{7}$

En cuanto concierne a la buena fe objetiva, se le ha entendido como "principio jurídico que introduce en el contenido de las obligaciones deberes coherentes con un modelo de comportamiento objetivo", que se expresa a través de las reglas de honestidad y corrección propias de dicho modelo. De manera que este tipo de buena fe se erige en regla de conducta fundada en la honestidad, en la rectitud, en la lealtad y principalmente en la consideración del interés del otro visto como un miembro del conjunto social que es jurídicamente. La buena fe objetiva presupone que se actúe con honradez, probidad, honorabilidad, transparencia, diligencia, responsabilidad y sin dobleces, entre otros deberes que emanan de permanentemente de su profuso carácter normativo.

Entendemos que la expresión "buena fe subjetiva", que de manera general ha sido considerada como "un estado de ignorancia y error", denota un estado de conciencia, convencimiento; y se dice subjetiva justamente porque para su aplicación debe el intérprete considerar la intención del sujeto de la relación jurídica, su estado psicológico, su íntima convicción; se trata por lo tanto de una idea de ignorancia, de creencia errónea acerca de la existencia de una situación regular, la cual se funda en el propio estado de ignorancia, o en la errónea apariencia de cierto acto, que se concreta en el convencimiento del propio derecho o en la ignorancia de estar lesionando el derecho ajeno. Entonces la buena fe subjetiva no se predica respecto "al contenido o a los efectos de la relación misma", sino que se refiere exclusivamente a la corrección del sujeto dentro de la relación jurídica, esto es, a la conciencia del sujeto en relación con la propia situación, o con la ajena, de la que deriva su derecho", de no estar dañando un interés ajeno tutelado por el derecho.

\footnotetext{
${ }^{7}$ Guillermo Borda Revista Signos Universitarios año 1991 - Miscelania II - Nro. 20, pág. 41, Ediciones
} Universidad del Salvador. 
El realizar una adecuada distinción de los conceptos de buena fe objetiva y subjetiva contribuirá a establecer el campo en el que opera la presunción de la buena fe, así como el justo alcance de ésta.

\section{Funciones}

Los principios generales del derecho son ciertas directrices anteriores y superiores al ordenamiento positivo, y que por lo tanto no requieren de una necesaria consagración positiva, en el Código Civil y Comercial de la Nación cumpliendo funciones básicas: informadora; integradora, y correctora de derechos. (algunos hablan de interpretativa respuestas o interpretación del P.J)

La función informadora supone dotar de sentido y sistematizar un ordenamiento jurídico dado. De esta manera, se le infunde sentido y valor a las formulaciones jurídico-técnicas a objeto de que dicho ordenamiento sea más congruente con las exigencias de lealtad y honestidad que debe inspirar la conducta de los sujetos, respondiendo de esta manera a las exigencias del principio de responsabilidad negocial. En razón de lo anterior, la buena fe permite sostener un vínculo entre el mundo jurídico y el sistema de valores socialmente aceptados. Esto evita que el Derecho sea concebido como una estructura neutra o de mera geometría social, abriendo paso a una moralización del sistema jurídico. A mayor abundamiento, esta función informadora del sistema jurídico, que ostenta la buena fe, permite concluir que el Derecho no es puro formalismo y que la aplicación de sus normas exige una conexión con el sistema de valores. Esta función informativa da la debida coherencia y unidad a nuestro ordenamiento jurídico, integradora e interpretativa.

La función de integradora de normas. Esta función resulta esencial en el contenido del negocio jurídico, toda vez que la voluntad de los contratantes -al igual que en el caso del legislador- es incapaz de prever todas las posibilidades que se derivan del acto jurídico. A diferencia de lo que señala el positivismo ideológico, los principios generales del derecho, y entre ellos la buena fe, permiten completar y rellenar los vacíos de la legislación o del acuerdo contractual, cerrando el sistema legal. Lo anterior asegura que el ordenamiento jurídico sea visto como un sistema completo, pleno y sin fisuras. Resaltando la función de 
integración de la ley, con otras fuentes del derecho determinando el verdadero sentido y alcance de los preceptos teniendo en consideración los usos, prácticas y costumbres para obtener soluciones equitativas. En los contratos la buena fe termina creando deberes y obligaciones que son claramente apreciables desde una perspectiva objetiva de la misma. Dicho de otra manera, los deberes de corrección y honradez, tan propios de una buena fe objetiva, se integran en la relación jurídicos llenando las lagunas y los vacíos dejados por las partes contratantes. Dentro de este esquema, la invocación de la buena fe permitirá proteger la confianza general (base del tráfico jurídico), interpretar los puntos oscuros, fijar el contenido de la declaración de voluntad y resolver las dificultades de aplicación de los acuerdos contractuales. La buena fe está destinada de manera principal a los ciudadanos y no al juez importa la integración de la voluntad no solo la contractual incluye las manifestaciones unilaterales (art.1800 C.C.y C.N), situaciones jurídicas familiares matrimoniales y uniones convivenciales como así también las conductas que "resultan sobreentendidas conforme a los usos ,las costumbres, la equidad" ${ }^{8}$.- no se limita a fuente formal del derecho y a lo expresado por las partes en forma expresa o tácita (art. 291 C.C. y C.N) incluyendo lo que verosímilmente entendieron o pudieron entender obrando con cuidado y previsión . Y esta función termina siendo una consecuencia natural del carácter que tiene la buena fe como principio general del Derecho.

La buena fe tiene una función correctora y limitativa de derechos. Ante el ordenamiento jurídico no existen derechos absolutos ni libertades abusivas, por tanto resulta natural concluir que la buena fe constituye una herramienta de corrección en el ejercicio de los derechos subjetivos la función correctiva es una consecuencia de la integración de la ley y de la integración de la voluntad con efectos habituales, la interpretación por el órgano jurisdiccional llevara a cotejar este deber de no dañar y el deber de realizar ciertos actos lealmente con la necesidad de corregir el ejercicio de las obligaciones creadas por las voluntad particular o cuando la posición particular de una parte respecto de la otra conlleve a que el ejercicio de lo pactado tenga consecuencias disvaliosas. Dicha corrección se expresará, por ejemplo, en el reconocimiento de una responsabilidad derivada del injusto receso de las tratativas, en el quiebre de la confianza legítima o en el ejercicio 
contradictorio de una posición jurídica, en el abuso de la nulidad por motivos formales; en la anulación de actos abusivos de la parte dominante, en la prohibición del poder formativo de resolución si el cumplimiento fue sustancial, en la aplicación de la teoría de los actos propios(Venire contra factum proprium),en la prohibición de invocar abusivamente la excepción de contrato no cumplido, en accionar judicialmente para exigir algo que el mismo demandante debe restituir por otro motivo; o bien cuando se impide la exigibilidad de un derecho si el titular permaneció inerte por largo tiempo, generando en la contraparte la expectativa legítima de que el mismo no sería ejercido (el retraso desleal del Derecho alemán), entre otras varias alternativas. Lo que ocurre es que, con la aplicación de este principio, se pretende superar una lógica meramente formal y avanzar hacia un estadio en que la conducta de los contratantes se ajuste con la idea de lo justo y razonable. Por cierto, esto no implica que las partes tengan que ejecutar deberes extraordinarios o distintos de aquellos que les imponen el contrato o la normativa vigente. Simplemente, lo que se busca es que el actuar del trabajador y del empleador tenga como elemento moralizador criterios de honradez, lealtad y colaboración.

\section{Principio de buena fe en los contratos}

En materia contractual el pilar sobre el que se asienta la negociación y la ejecución de los contratos es el de la autonomía de la voluntad, que presupone la libertad de contratación de las partes, con carácter dinámico y rodeado por una serie de institutos correctores o límites, como el Abuso de Derecho, la Imprevisión, la aplicación de las Leyes de protección al Consumidor, la teoría de los Actos Propios y sobre todo la interpretación del negocio jurídico mediante la pauta o criterio de la "buena fe" contractual, abarcando ésta todo el periodo, desde las negociaciones previas hasta la etapa post-contractual. ${ }^{9}$

El Código Civil y Comercial de la Nación establece nuevas reglas, las cuales fueron recogidas del Código Civil de Vélez Sársfield y del Código de Comercio, evolucionando las mismas a través de la doctrina y la jurisprudencia y dirigidas tanto a las partes de un contrato como al juez que debe solucionar una disputa contractual e interpretar lo que las

${ }^{9}$ Garrido Roque F.- Zago Jorge A. Notas: Contratos Civil y Comercial, Ed. Universidad

\begin{tabular}{llll}
\hline \hline ANUARIO DE DERECHO CIVIL & TOMO XIII & 2019 & Página 189
\end{tabular}


partes acordaron. Podemos clasificar a los contratos en 1) Negociales 2) Consumo 3) Adhesión; estableciendo pautas para redactar contratos, en consideración a la interpretación judicial aplicando los criterios hermenéuticos del C. C...yC. N.

ARTICULO 961.-Buena fe. "Los contratos deben celebrarse, interpretarse y ejecutarse de buena fe. Obligan no sólo a lo que está formalmente expresado, sino a todas las consecuencias que puedan considerarse comprendidas en ellos, con los alcances en que razonablemente se habría obligado un contratante cuidadoso y previsor”.

La "buena fe" es un principio aplicable en general a todo ejercicio de los derechos subjetivos (art. 9) y, muy especialmente a los contratos. Incluye tanto la buena fe en el sentido de un comportamiento leal (buena fe objetiva), como la denominada "buena fecreencia" (subjetiva), que incluye la llamada "apariencia creada". Los contratos obligan "no sólo a lo que está formalmente expresado, sino a todas las consecuencias que puedan considerarse comprendidas en ellos, con los alcances en que razonablemente se habría obligado un contratante cuidadoso y previsor" (art. 961).

En cuanto al significado de las palabras empleadas que éstas deben entenderse en el sentido del uso común, la buena fe en la celebración del contrato obliga a las partes a expresar sus ideas con claridad." Para eliminar la ambigüedad y vaguedad del lenguaje y de las palabras se ha destacado que es relevante mirar el "contexto" de situación fáctica en que el lenguaje se usa", excepto que la ley le otorgue un significado específico, del acuerdo de las partes o de los "usos y costumbres del lugar de celebración" (art. 1063).

Es cierto que la "buena fe" es una pauta para la interpretación del contrato, ya que es ella la que ordena las conductas probas, leales, dignas y descarta todo procedimiento contrario y también es la que manda ajustarse a la apariencia a lo que el otro contratante pueda entender o creer para no defraudar la confianza suscitada. El Código Civil y Comercial de la Nación en sus fundamentos expresa que en la realidad negocial moderna existe desde que las partes entraron en conversaciones con miras a la celebración de un contrato, esto es, antes de que haya sido emitida una oferta, en esta etapa las partes deben comportarse de "buena fe" para no frustrar injustamente, las tratativas contractuales, y además debe ponerse al alcance de la otra futura parte, toda la información adecuada de los hechos relativos al contrato, que puedan tener actitud para influir sobre su decisión de aceptar. Las 
partes, también deben actuar de "buena fe" durante la ejecución del contrato, se generan obligaciones secundarias, que abarcaría a lo que razonablemente se había obligado un contratante cuidadoso y previsor, se incluye las consecuencias virtualmente comprendidas en el contrato, conforme a la naturaleza, a las negociaciones previas, a la conducta ulterior, a las prácticas establecidas entre las partes, a los usos no excluidos expresamente, y a la equidad, teniéndose siempre presente, la finalidad del acto y las expectativas justificadas de la otra parte. Como se ve, es esencial la idea de que el contratante se obliga en la medida que genera confianza en la otra parte. En lo específico de la materia interpretativa en el ámbito contractual, se le asigna especial relevancia a la interpretación de "buena fe", se referencia la común intención de las partes, por sobre a la literalidad de lo manifestado, al sentido que razonablemente hubiera atribuido a la manifestación, una persona en la situación y de las condiciones de la otra y se propone la aplicación a aquellos contratos que contengan cláusulas que permitan a una de las partes modificar lo convenido a su arbitrio. Es interesante que se haya receptado que cuando una de las partes actúa profesionalmente, para que la interpretación opere conforme a la pauta de "buena fe", debe tomarse especialmente en cuenta la adecuación a las pautas razonables de actuación real en la actividad en la que corresponde el contrato.

Con la reforma se ha consagrado expresamente el principio de la "buena fe" siguiendo en ello al Código Italiano cuyo artículo 1136 prescribe: "El contrato debe ser interpretado según la "buena fe" y concuerda con el parágrafo 157 del Código Alemán en el que se manifiesta: "Los contratos han de interpretarse como exigen la fidelidad y la "buena fe" en atención a los usos del tráfico".

Análisis del art. 756 (orden de prelación)

ARTÍCULO 756.- Concurrencia de varios acreedores. Bienes inmuebles. Si varios acreedores reclaman la misma cosa inmueble prometida por el deudor, son todos de buena fe y a título oneroso, tiene mejor derecho: a) el que tiene emplazamiento registral y tradición; b) el que ha recibido la tradición; c) el que tiene emplazamiento registral precedente; d) en los demás supuestos, el que tiene título de fecha cierta anterior.

El artículo plantea la situación cuando un deudor celebra acuerdos con diferentes sujetos, en virtud de los cuales promete la entrega de una misma cosa para constituir derechos 
reales sobre ella. No hay dudas de que, en estos supuestos, la mala fe del deudor resulta clara, pero no así la del acreedor que puede o no saber que la cosa había sido prometida a otro sujeto. La ley establece un orden de preferencia según la situación jurídica en la que se encuentre cada acreedor, tanto se trate de cosas muebles como inmuebles. Cabe recordar que el art. 750 C.C. yC.N, establece que "el acreedor no adquiere ningún derecho real sobre la cosa antes de la tradición, excepto disposición legal en contrario". Este es un elemento de mucha importancia porque si la cosa prometida se encuentra sometida a registración y las normas específicas de dicho registro establecen que la inscripción tiene carácter constitutivo, entonces el acto de inscripción desplazará al principio de tradición para que quede perfeccionado el derecho real en cabeza del acreedor. Pero la tradición no es el único requisito para la adquisición del derecho real sobre inmuebles, sino que requiere la concurrencia de título suficiente. Este último es el acto jurídico revestido de las formas establecidas por la ley, que tiene por finalidad transmitir o constituir el derecho real.

Análisis del art. 392

El art. 392 es similar al art. 1051 (texto según ley 17.711) del Código Civil sustituido conservando el efecto retroactivo de la sentencia de nulidad en relación a los terceros a quienes se le transmiten cosas registrables y protegiendo a los subadquirentes de buena fe y a título oneroso de derechos sobre inmuebles; incorporando protección a los bienes muebles registrables. Se excluye de esta protección a los subadquirentes en virtud de un acto realizado sin la intervención del titular del derecho (transmisiones a non domino).

Se consagra el efecto retroactivo de la sentencia de nulidad respecto de los terceros en cosas registrables. El tercero a quien el adquirente por acto nulo ha transferido la propiedad de una cosa registrable u otro derecho sobre la misma, es alcanzado por la sentencia de nulidad y privado, en consecuencia, de esos derechos, este sería el principio.

La protección al subadquirente de buena fe y a título oneroso seria la excepción de la norma, respecto de los terceros subadquirentes de derechos reales, exige buena fe y a título oneroso. De tal modo, estos terceros no se encuentran alcanzados por el efecto retroactivo de la sentencia de nulidad y en consecuencia tampoco están obligados a la restitución. Para que opere tal protección deben reunirse los siguientes requisitos, a saber: a) Debe ser 
invocada por un tercero subadquirente que es quien recibe, por un acto válido y a título oneroso, un derecho real registrable de un sujeto que a su vez lo adquirió en razón de un acto nulo. De tal modo, supone una anterior adquisición por acto nulo y una posterior adquisición onerosa y de buena fe; esta última es la tutelada, impidiéndose sobre ella la reivindicación. Es decir, no corresponde invocar la defensa de la apariencia jurídica al primer adquirente por acto nulo sino al subadquirente posterior, tercero respecto de ese acto.

b) Tratarse a derechos reales sobre inmuebles registrables Quedan excluidos de la protección de la norma los derechos adquiridos por terceros sobre cosas muebles no registrables, que tienen un régimen propio.

Tratándose de derechos reales sobre inmuebles, el acto en cuya razón se los ha constituido a favor del subadquirente debe estar extendido en escritura pública (art. 1017). Respecto a la necesidad de inscripción registral (art. 1893) para su oponibilidad. c) El acto en razón del cual se constituyen los derechos reales a favor del subadquirente, debe ser un negocio jurídico oneroso. La onerosidad que exige el art. 392 se refiere sólo al acto jurídico que fuera causa de la adquisición del derecho por el subadquirente y no a los actos jurídicos anteriores, incluido el que motivó la sentencia de nulidad cuya calidad de oneroso o gratuito es indiferente a los fines de la protección que brinda la norma. Buena fe. Estudio de títulos La norma se refiere al subadquirente de buena fe y alude a la buena fe creencia, es decir aquella que se predica de quien se persuade de la legitimidad de su título.Tratándose de la adquisición de derechos reales sobre inmuebles, se discute acerca de cuáles deben ser las diligencias que emplee el subadquirente para satisfacer el recaudo de buena fe. Un sector minoritario de la doctrina considera que basta la buena fe registral. Ella existe cuando el tercero adquiere de quien figura en el Registro de la Propiedad Inmobiliaria como titular del dominio de acuerdo al certificado que expide ese organismo (Spota, Lloveras de Resk).

En contra de esta opinión, se alza la mayoría de la doctrina nacional que exige, como recaudo de buena fe, que el subadquirente haya hecho el estudio de títulos, no bastando para acreditar la buena fe la mera comprobación de quien es el titular registral. Destacando al respecto, que el art. $4^{\circ}$ de la ley 17.801 (Ley Nacional Registral) establece que: "La 
inscripción no convalida el título nulo ni subsana los defectos de que adoleciera según las leyes " (Pérez Lasala, Highton, Rivera, Trigo Represas, Guastavino).

En el estudio de títulos se trata de analizar los negocios jurídicos que causaron sucesivas transmisiones o constituciones de derechos reales por el término de la prescripción adquisitiva, para determinar si esas transmisiones han sido regulares o son susceptibles de ser cuestionadas en su validez.

Respecto a la prueba de la buena fe, debe ser provista por el subadquirente. La buena fe del transmitente no es un recaudo exigido por la norma (Lloveras de Resk, Rivera). La falta de alguno de los recaudos antes mencionados significa volver al principio general establecido en la primera parte del art. 392. En consecuencia, el subadquirente estará obligado a restituir la cosa registrable al primer enajenante que obtuvo a su favor sentencia de nulidad, libre de los derechos reales o personales que se hubieran constituido a su favor.

En tal caso, la pretensión restitutoria del primer enajenante se endereza a través de la acción reivindicatoria; salvo que el subadquirente hubiere sido parte en el proceso que juzgó la nulidad de la primera enajenación, en cuyo caso podría ejercerse en ejecución de sentencia, por ser la restitución un efecto natural de la sentencia de nulidad (Lloveras de Resk, Malicki). Nulidades comprendidas Quedan comprendidas en la protección, tanto las nulidades relativas como las absolutas (Zannoni, Andorno, MossetIturraspe, Rivera, Malicki). En contra, algunos autores, en posición minoritaria, enajenación estaba fulminada por una nulidad absoluta, debe ceder la protección al tercero en aras del interés general afectado por una nulidad de este tipo (Llambías, Trigo Represas). Transmisiones a non domino La transmisión a non domino es aquella causada en un acto que ha sido otorgado por quien no es el titular del derecho de propiedad transmitido, ni se encuentra legitimado para representarlo. Es decir, aquellas en las cuales no participa el verdadero propietario en el acto de transmisión al adquirente; ocupando alguien su lugar. El art. 392 expresamente excluye de la protección al subadquirente de un inmueble o de una cosa mueble registrable cuando la primitiva enajenación ha sido actuada a non domino; disponiendo que los subadquirentes no pueden amparase en su buena fe y título oneroso si el acto se ha realizado sin la intervención del titular del derecho. Idéntica solución consagra el segundo párrafo del art. 2260.La solución del Código recepta la opinión de la doctrina mayoritaria 
que, con distintos fundamentos y matices, se había expedido en igual sentido al interpretar el derogado art. 1051 in fine. Algunos autores fundamentaron la exclusión por considerar que las trasmisiones a non dominio constituyen actos inexistentes (Belluscio, Highton, Borda, Llambías); o bien actos inoponibles (Alterini, Jorge, Trigo Represas); y por ende no comprendidos en la última parte del art.1051 que sólo aludía a los actos nulos o anulables. Otros autores la excluyeron por estimar que la acción de reivindicación a la que estaría legitimado el verdadero propietario se funda en la desposesión ilícita que ha sufrido. La nulidad del acto de transmisión a non domino es consecuencia de la reivindicación, pero no la precede; teniendo la cuestión solución propia en las normas específicas (Zannoni, Rivera). En posición minoritaria alguna doctrina interpretó que las transmisiones a non domino no estaban excluidos de la protección del art. 1051 in fine por tratarse de actos nulos (Mosset Iturraspe, Lloveras de Resk). Opinión que se reformula, con fundamentos que no compartimos, al interpretarse la norma vigente; entendiéndose que será el análisis de las circunstancias en que se produjo la adquisición a non domino lo que determinará la buena o mala fe del tercer adquirente a título oneroso. Destacando que la falta de intervención del titular del derecho transmitido puede haber quedado oculta y no haberse percibido, a pesar de toda la diligencia empleada por éste. Se concluye así: "que llevar la adquisición a "non domino" a la categoría de impedimento esencial específico " para aplicar el principio contenido en el art. 392 importa un retroceso en la aplicación de los principios atinentes a la seguridad dinámica del derecho (Etchegaray).

\section{Jurisprudencia}

- Es recaudo de buena fe que el subadquirente haya hecho el estudio de títulos, pues la exigencia de buena fe no se satisface con la mera comprobación de quien es el titular registral (SCBA, 7/11/1995, Lexis, 14/36989).

Análisis del art. 1892.- Título y modos suficientes. La adquisición derivada por actos entre vivos de un derecho real requiere la concurrencia de título y modo suficientes. Se entiende por título suficiente el acto jurídico revestido de las formas establecidas por la ley, que tiene por finalidad transmitir o constituir el derecho real. La tradición posesoria es modo 
suficiente para transmitir o constituir derechos reales que se ejercen por la posesión. No es necesaria, cuando la cosa es tenida a nombre del propietario, y éste por un acto jurídico pasa el dominio de ella al que la poseía a su nombre, o cuando el que la poseía a nombre del propietario, principia a poseerla a nombre de otro. Tampoco es necesaria cuando el poseedor la transfiere a otro reservándose la tenencia y constituyéndose en poseedor a nombre del adquirente. La inscripción registral es modo suficiente para transmitir o constituir derechos reales sobre cosas registrables en los casos legalmente previstos; y sobre cosas no registrables, cuando el tipo del derecho así lo requiera. El primer uso es modo suficiente de adquisición de la servidumbre positiva. Para que el título y el modo sean suficientes para adquirir un derecho real, sus otorgantes deben ser capaces y estar legitimados al efecto.

Análisis del art. 1893 del código civil y comercial de la Nación

En nuestro sistema se puede afirmar que para producir una mutación jurídico real, en materia inmobiliaria, hace falta un título suficiente (escritura pública -arts. 1184 Cód. de Vélez y 1017 del nuevo Código), y un modo suficiente (traditio -arts. 577 del Cód. de Vélez y 750 del nuevo Código), requisitos que se complementan con la inscripción del título en el Registro para lograr plena oponibilidad (arts. 2505 del Cód. de Vélez y 1893 del nuevo Código).

Hablamos de la oponibilidad relacionándola con la publicidad, es necesario primero determinar el momento en el que nace el derecho. Si estamos frente a un registro constitutivo nace con la inscripción como el registro del automotor. En cambio, si se trata de un registro declarativo el derecho nace fuera del registro (ej inmuebles) aquí hay que destacar que en artículo se reconoce no solo la publicidad registral sino también se reconoce la publicidad posesoria.

- Resulta plenamente vigente toda la jurisprudencia elaborada desde 1968 siendo el principio de buena fe supremo y absoluto dominando todo el derecho obligacional (C.N. Civ.sala F 5/3/1985, Ed. 117-656)

La reforma ha tenido presente una calificada jurisprudencia nacional que venía sosteniendo en cuanto a la interpretación de un contrato, se debe investigar la voluntad real de las 
partes, sin atenderse al sentido literal de las expresiones empleadas, ya que la voluntad, no consiste sólo en los términos con que se exterioriza, sino en las circunstancias externas con las cuales ha podido contar el autor de la declaración, para determinar el alcance exacto de ellas y tal interpretación se debe regir por los principios de "buena fe".

La jurisprudencia nacional, basada en fallos de tribunales ingleses, ha decidido que ante palabras claras, no se admite la prueba de intención distinta mediante testigos; se protege, así, la seguridad del tráfico comercial. Cabe, no obstante, la decisión contraria, si se prueba sin lugar a dudas que ambas partes interpretaron los términos de otra manera. (Guillermo borda)

- Mantiene el criterio la jurisprudencia en cuanto a que los contratos deben celebrarse, interpretarse y ejecutarse de buena fe y de acuerdo con lo que las partes verosímilmente entendieron o pudieron entender, obrando con cuidado y previsión y que este principio cardinal de la buena fe informa y fundamenta todo nuestro ordenamiento jurídico, tanto público como privado, al enraizarlo en las más sólidas tradiciones éticas y sociales de nuestra cultura (CSJN, 17/4/2007, Fallos: 330:1649).

- Otro fallo en igual sentido nos dice que rige en su celebración, interpretación y ejecución, pues es el alma del comercio y de las relaciones civiles cabiendo en él la voluntad de obrar honestamente y la creencia en el propio derecho (C. Civ. Y Com Mercedes sala II 25/10/1984, Ed.114-690) y ampliando tenemos el reconocimiento como deberes secundarios de conducta cuyo incumplimiento genera obligaciones (C. Civ.y Com. Rosario, sala IV, 24/11/84, J 76153).-

\section{CONCLUSION}

A través de este trabajo analizamos el Principio de Buena Fe concluyendo que es de principal relevancia dentro de nuestro derecho positivo, observando que a través del tiempo ha evolucionado encontrando consagración legal en Argentina en la reforma de la Ley 17.711 del año 1968 lo incorporó en el artículo 1198 por primera vez cuando disponía que los contratos deben celebrarse de buena fe y ejecutarse e interpretarse del mismo modo, y 
aclara: de acuerdo a lo que las partes verosímilmente, entendieron o pudieron entender, actuando con previsión y cuidado (hoy receptado en el art.961 C. C. y C. N), hasta quedar plasmado como regla en nuestro Código Civil y Comercial de la Nación en el año 2015 con una ubicación de privilegio en el Capítulo 3 denominado Ejercicio de los Derechos, dentro del Título Preliminar en su art. 9 del Código Civil y Comercial de la Nación, erigiéndose como principio de carácter general que ilumina a todo el ordenamiento jurídico encontrándose sus norma conectadas entre sí a lo largo de todo el código. Entendiendo que el principio permite visualizar el negocio jurídico como un instrumento solidario de cooperación entre las partes para el logro de una finalidad en común (art. 291 C.C. y C.N). Estableciendo los parámetros como en el art. 392 la protección a terceros de buena fe no es cualquier protección se requiere para la buena fe título, modo y publicidad y en el art.756 nos da un orden de prelación quedando delimitada la actuación del hombre diligente, captando los valores tradicionales y esenciales, como son la confianza, la lealtad, la honradez o la rectitud de los hombres, el ordenamiento jurídico establece la calidad jurídica de conducta exigida con el convencimiento de haber obrado bien. El ordenamiento jurídico reconoce o admite que la autonomía privada como punto de partida, pero no hasta el punto de considerar que este tenga un sistema propio o autónomo, por el contrario, las reglas generales del juego siguen siendo las establecidas por el marco normativo en su conjunto y por tanto comparten una necesaria adecuación. Así, el principio de buena fe se hace presente, cumpliendo funciones básicas informadora, integradora y correctora de derechos y se extiende de igual forma, en el contenido de eticidad de cada acto que deba examinarse a la luz de las circunstancias particulares, direccionando las conductas humanas y en especial los actos y contratos que gobiernan la convivencia, de tal forma que estas prescripciones generales siempre serán aplicadas, no solo al acuerdo contractual, sino que también estarán llamadas a gobernar todo el proceso tanto de formación, como el de perfeccionamiento y ejecución.

Es así que consideramos que el Notario es abarcado por este principio en toda su carrera y ejercicio de la profesión. Por ello cada notario debe asumir un profundo compromiso ético consigo mismo y con la comunidad de contribuir activa y responsablemente a la consecución del bien común, a través de todos los medios que estén a su alcance. 
En él reposa la confianza y fe de las personas que requieren de su servicio y sabiduría. De él se espera un buen obrar que reúna todas las cualidades nombradas más arriba.

\section{BIBLIOGRAFIA}

- LORENZETTI (dir) Código Civil y Comercial, t.I pag.53).

- ALSINA ATIENZA, Dalmiro, Efectos Jurídicos de la "buena fe".

- DIEZ PICAZO, La doctrina de los propios actos. Edit. Bosch.

- ALTERINI, A.A Derecho de las Obligaciones Civiles y Comerciales Bs. As Abeledo Perrot 1996, pag. 150.

- BORDA, Guillermo Revista Signos Universitarios año 1991 - Miscelania II - Nro. 20, pág. 41, Ediciones Universidad del Salvador.

- LORENZETTI (dir)código -civil y comercial, t.I p.55)

- GARRIDO ROQUE F.- ZAGO Jorge A. Notas: Contratos Civil y Comercial, Ed. Universidad

- LORENZETTI, Ricardo L. Fundamentos del Proyecto, II.6.2., La interpretación de los contratos, Suplemento Especial Contratos, La Ley, 2015, pág. 198.

- GÓMEZ, Astrid y BRUERA, Olga María, Análisis del Lenguaje Jurídico, Ed. de Belgrano, 1981, Buenos Aires, págs. 67-68.

- RUIZ GÓMEZ, Juan Eugenio Cualidades y circunstancias que según la ciencia debe reunir el Notario en su persona". La Notar según la legislación y la ciencia, Madrid, España. 1879 